\title{
Dynamic Simulation of Harmonic Gear Drives Considering Tooth Profiles Parameters Optimization*
}

\author{
Huimin Dong \\ School of mechanical engineering, Dalian University of Technology, Dalian 116024, PR China \\ Email: donghm@dlut.edu.cn \\ Zhengdu Zhu, Weidong Zhou, Zhi Chen \\ zhu_0501@163.com, zhou_WDong@163.com
}

\begin{abstract}
Considering the fact that load distribution of the flexspline under alternating dynamic loads is complicated, and it's difficult to measure the stress of the flexspline by experiment, a dynamic simulation model of harmonic gear drives is established to study the intensity of the flexspline in the operating process of harmonic gear drives based on finite element method. In order to decrease the force on flexspline, by means of conjugate method, the parameters of flexspline and circular spline's tooth profiles are optimized. A D-100 harmonic drive is simulated based on the contact theory and the explicit algorithm of the finite element method. The parameterized finite element grid of the whole harmonic gear drive model is realized by Matlab, and then the assembly process of the wave generator is simulated by ABAQUS. Meanwhile, the distribution of the flexspline stress and the load characteristics of the flexspline tooth during dynamic transmission process of a harmonic gear with parameters, before and after optimization, are analyzed. The meshing characteristics of the tooth pairs with optimized parameters are improved significantly. The fatigue fracture position on the flexspline is forecasted according to the simulation results.
\end{abstract}

Index Terms-dynamic simulation; harmonic gear drives; finite element method; fatigue fracture; flexspline.

\section{INTRODUCTION}

Since Musser invented a new type of transmission called harmonic gear drives in the late 1950s, harmonic drives have been widely used in many industrial fields, especially in high performance control system for their high precision, compactness, light in weight properties and high reduction ratio characteristics compared with the conventional speed reducer. A harmonic drive works with periodic elastic deformation of a flexspline which is a spatial deformation element. Obviously, the deformation of the flexspline is of utmost importance,

Manuscript received April 15, 2011; revised June 1, 2011; accepted June 21, 2011.

Copyright credit, corresponding author: Huimin Dong

*The financial support of the National Natural Science Foundation of China No. 50975038 and the researchers made many efforts in this respect. Photoelastic method was adopted to study the concentrated root stress of flexspline in [1], the stress distribution of flexspline was measured by experiment. However, for the complex of harmonic drives, the author simplified flexspline tooth and structure. Thus, some parameters are difficult to be obtained by experiment method, which has great limitation and high cost. Later scholars mostly adopted finite element method to analyze the intensity of the flexspline. Due to the difficulty of modeling and the great amount of calculation, they simplified the model and boundary conditions in [2-4], and only conducted static contact analysis without taking into account the dynamic characteristics of the whole harmonic drives under the effect of variable load which leads to biggish deviation in the analysis results. 3D FEM [7] is adopted to check the flexspline strength, able to predict the flexspline failure position under the static state.

Dynamics method has been extensively applied in the structure analysis. The structural dynamic problems often have two types, one is structure or mechanism in the movement, such as turbine, which possess the inertia of itself and dynamic load produced by interaction of medium surrounding and structure; the other is engineering structure that bears dynamic loading. A harmonic drive can transform the motion and moment from input to output due to the flexspline periodic elastic deformation, which belongs to the first kind of dynamics problems. The main failure form of harmonic drives is the flexspline fatigue fracture due to the flexspline periodic deformation.

This paper takes a D-100 type harmonic drive as an analyzing example. The tooth profile parameters are optimized in order to fit the conjugate numerical results obtained by conjugate model [16]. A simulation model is established, which is close to the actual situation in a harmonic drives operating to the largest extent. In consideration of the contact, dynamic load impact, meshing interference between the flexspline and the circular spline tooth, and the stress, strain of the flexspline varying along with motion of the harmonic 
drive under the nominal load, the dynamic simulation is conducted using Abaqus/Explicit in Abaqus. The simulating results with parameters before and after optimization are compared. Finally, the position where flexspline is prone to arise fatigue fracture is to be predicted, meanwhile, the circumferential meshing rule of the flexspline tooth is studied.

\section{OPTIMIZATION OF TOOTH PROFILE PARAMETER}

\section{A. The determination of the conjugate tooth profile}

A harmonic gear drive with flexspline cup consists of three components, a rigid circular spline with internal teeth, a wave generator and a flexspline with external teeth. The flexspline is the key element in a harmonic drive, because of its periodic elastic deformation caused by the wave generator. The profile curve of the wave generator is:

$$
R(\varphi)=R_{0}+w_{0} \cos 2 \varphi
$$

where $R_{0}$ is the radius of flexspline neutral circle; $w_{0}$ is a constant coefficient of the wave generator.

In Ref. [16], the neutral layer deformation of the flexspline cup on each cross section under no-load condition has been discussed, which can be expressed in terms of $\varphi$ (the independent argument) and $\mathrm{z}$ as are

$$
\left\{\begin{array}{l}
\mathrm{u}=-\frac{z}{L_{0}} m \cos 2 \varphi, \mathrm{v}=\frac{z}{2 L_{0}} m \sin 2 \varphi \\
\varphi_{\mathrm{fF}}=-\frac{3 z}{2 L_{0}} \frac{m \sin 2 \varphi}{\left(\left(R_{0}+\mathrm{u}\right)^{2}+\mathrm{v}^{2}\right)^{1 / 2}}
\end{array}\right.
$$

where $\mathrm{u}, \mathrm{v}$ and $\varphi_{f F}$ are radial and circumference and angular displacement relative to the neutral circle respectively; $L_{0}$ refers to the midsection of the face width; $\mathrm{z}$ is the length measured from the closed end of the cup to the cross section along the rotating axis;.

Let the circular spline be a spur gear with an involute profile. The tooth profile at the right side and the continue direction of the profile are written as $[8,16]$ :

$$
\left\{\begin{aligned}
r_{C i}= & \frac{r_{b C}}{\cos \alpha_{i}}, \delta_{C}=\frac{\pi}{2}-\alpha_{i}+\mu_{C} \\
\mu_{C}= & \frac{1}{2 N_{C}}\left(\pi+4 \xi_{C} \tan \alpha\right)+, \alpha_{i} \in\left[\alpha_{a}, \alpha_{d}\right] \\
& \quad{\operatorname{inv} \alpha-\operatorname{inv}_{f i}}
\end{aligned}\right.
$$

where $r_{b c}$ is the base circle radius; and $\alpha_{a}, \alpha_{d}$ is the addendum and dedendum pressure angle respectively; $\xi_{C}$ is the modification coefficient.

The conjugate condition of the harmonic drive satisfy the conventional gearing conjugate principle : $\mathbf{V}^{f C} \cdot \mathbf{n}^{C}=0$. When the wave generator is fixed and the circular tooth profile is given, the conjugate condition in each cross section can be expressed as [16]

$$
\begin{array}{r}
{\left[\dot{\mathrm{v}}+\mathrm{R}_{\mathrm{u}}\left(1-\omega_{f}\right)\right] \sin \psi_{\mathrm{C}}+\left[\dot{\mathrm{u}}-\mathrm{v}\left(1-\omega_{f}\right)\right] \cos \psi_{\mathrm{C}}} \\
+\mathrm{r}_{C}\left(\omega_{\mathrm{f}}-\omega_{\mathrm{C}}\right) \sin \left(\delta_{C}-\mu_{C}\right)=0 .
\end{array}
$$

where $\mathrm{R}_{\mathrm{u}}=\mathrm{R}_{0}+\mathrm{u}, \psi_{C}=\delta_{C}+\varphi_{C}-\varphi$.

Based on the above analysis, if the desired transmission ratio and the cup deformation are given, with a prescribed circular spline tooth profile, the conjugate point $\left(x_{C}, y_{C}\right)$ and its position angle $\varphi$ can be obtained by (4). Thus, the complete flexspline profile corresponding to the meshing point can be obtained by the coordinate transformation from circular spline coordinate system flexspline coordinate system [16].

\section{B. The optimization of tooth profile parameter}

According to the method of determining the conjugate tooth profiles, with wave generator parameter and involute tooth profile of circular spline as known parameters, the corresponding conjugate flexspline tooth profile can be obtained. However, the numerical solution of mathematical model based is a series of discrete points. Considering manufacturing process characteristic, the involute is adopted as actual tooth profiles. Thus, involute is used to fit those theoretical discrete points. An optimal model with smallest fit error is established to confirm the best involute parameters.

Let $x_{1}$ and $x_{2}$ (modification coefficients of the flexspline and circular spline tooth profile) represent the optimization variables. The involute equation is used to approximate to the discrete data of the conjugate tooth profile, it can be described as $\left\{x_{i n v}^{C}\right\}=F\left(x_{1}, \lambda_{1}\right)$, which is related to $x_{1}$; the discrete data of the conjugate tooth profile is: $\left\{x_{M}^{f}\right\}=G\left(x_{2}, \lambda_{2}\right)$, which is related to $x_{2}$. The optimal objective function indicating the shortest distance between the point $\left\{x_{M}^{f}\right\}_{i}$ and $\left\{x_{i n v}^{C}\right\}$ on involute can be written as:

$$
\begin{aligned}
D_{i}=H\left(x_{1}, x_{2}, \lambda_{1}, \lambda_{2 i}\right) & =\min \left(\operatorname{distance}\left(\left\{x_{M}^{f}\right\}_{i},\left\{x_{i n v}^{C}\right\}\right)\right) \\
i & =1,2,3, \ldots, \mathrm{N}
\end{aligned}
$$

TABLE I.

The BASIC PARAMETERS OF D-100HARMONIC GEAR DRIVE

\begin{tabular}{|c|c|c|}
\hline & Flexspline & Circular spline \\
\hline Number of tooth & 100 & 102 \\
\hline Module & 1 & 1 \\
\hline Pressure angle & 20 & 20 \\
\hline $\begin{array}{c}\text { Initial modification } \\
\text { coefficient }\end{array}$ & 3.05 & 2.9 \\
\hline $\begin{array}{c}\text { Addendum coefficient } \\
\text { Bottom clearance } \\
\text { coefficient }\end{array}$ & 0.75 & 0.75 \\
\hline
\end{tabular}

A calculation example based on the conjugate theory will be conducted, the basic parameters of harmonic gear is given in Table $\mathrm{I}$. 
The tooth profile of the circular spline can be solved based on (3); for each cross section, $u, v, \varphi_{f F}$ and their derivative ( $\dot{\mathrm{u}}, \dot{\mathrm{v}}$ and $\dot{\varphi}_{f F}$ ) are found from (2). Then, substituting them into (4) and solving the equation yields the position angle $\varphi$; thus, the flexspline profile corresponding to the meshing point can be obtained. Fig. 1 shows the theoretical conjugate tooth profile of flexspline on the $1^{\text {st }}$ cross section.

Hence, the optimization model can be established:

$$
\begin{cases}\min & \max _{D_{i}}\left\{D_{i}=H\left(x_{1}, x_{2}, \lambda_{1}, \lambda_{2 i}\right)\right\}, i=1,2,3, \ldots, \mathrm{N} \\ \text { s.t. } & \left\{x_{M}^{f}\right\}=G\left(x_{2}, \lambda_{2}\right)=B^{-1}\left(B_{F}^{-1}\left\{x_{M}^{C}\right\}-\left\{x_{O f}^{F}\right\}\right) \\ & \left\{x_{i n v}^{C}\right\}=F\left(x_{1}, \lambda_{1}\right) \\ & \mathrm{x}_{1}, \mathrm{x}_{2}>0\end{cases}
$$

where $\mathrm{N}$ is the number of the conjugate point.

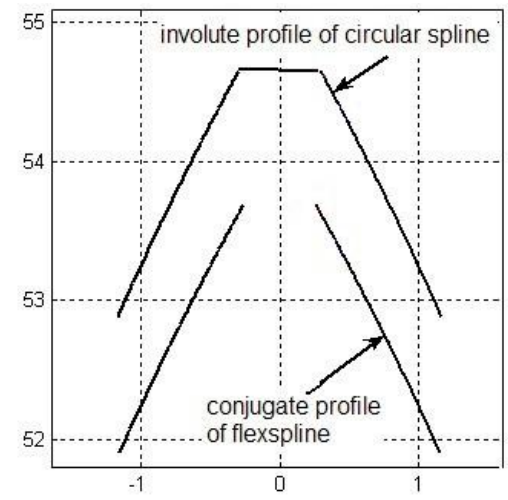

Figure 1. The theoretical conjugate tooth profile of flexspline.

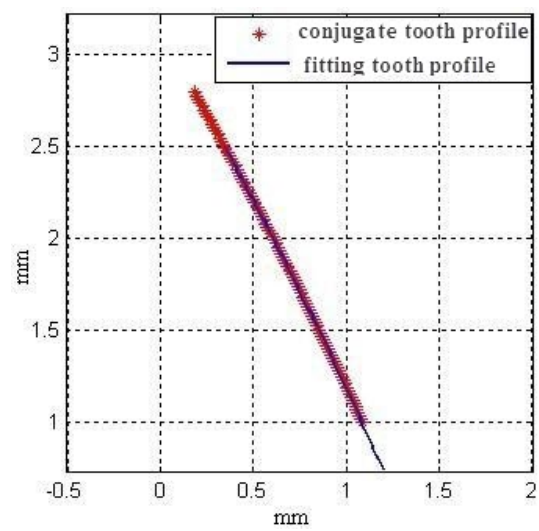

Figure2. The approximating curve of flexspline tooth profile.

The optimization model (6) needs to be solved by numerical calculating method. In this paper, the optimization method solving minimization of maximum value is adopted. The expression is:

$[x, f v a l]=$ fminimax $\left(\begin{array}{l}\text { fun, } x_{0}, A, b, \text { Aeq }, \text { beq }, \\ l b, u b, \text { nonlcon, options }\end{array}\right)$

where fun is the objective function; $x_{0}$ is the initial value of optimization variables, $x_{0}=\left[x_{1}, x_{2}\right]=[3.05,2.9]$; $l b, u b$ are limit optimizing variables, in the range of $[l b, u b]$ to ensure $x_{1}, x_{2}>0$; the rest of the parameters is set to null. With the function iteration completed, the optimal solution $x$ and error fval can be obtained, $x=[3.0494,3.0290]$. The approximating curve is shown in Fig. 2 and the approximating error of the maximum error point is $0.007 \mathrm{~mm}$.

The flexspline tooth along the rotating axis is divided into 21 cross sections. For each cross section, the radial deformation coefficient $w_{i}(i=1,2, \ldots .21)$ have different values, which is a linear function along the rotating axis, the expression is:

$$
w_{i}=\frac{w_{0} l_{i}}{L-B}+w_{0}
$$

Where $w_{0}$ is the radial deformation coefficient of the wave generator; $l_{i}$ is the distance between the $i$ cross section and the first cross section (the left side tooth profile); $L$ is the length of the cup flexspline.

Based on $w_{i}$, the deformation function of different cross section can be solved. According to (4), the theoretical conjugate space tooth profile of flexspline is obtained shown in Fig. 3

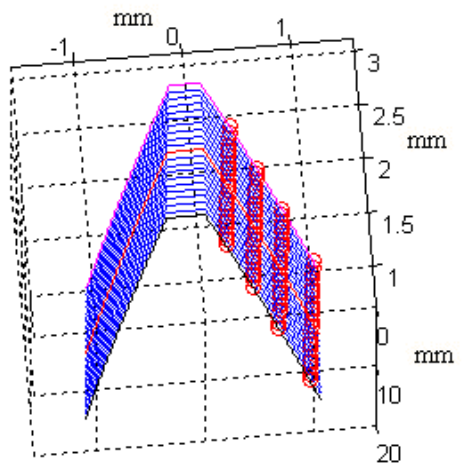

Figure3. The 3D view of theoretical conjugate profile of flexspline

\section{THE FINITE ELEMENT MODEL AND THE DYNAMIC SIMULATION METHOD}

A. Finite Element geometric Model

A harmonic gear drive consists of three components, a

TABLE II.

StruCture PARAMETERS OF THE FleXSPLINE CuP

\begin{tabular}{|c|c|}
\hline$d_{1}$ & 100 \\
\hline $\mathrm{L}$ & 100 \\
\hline$\delta$ & 1.1 \\
\hline$\delta_{1}$ & 0.9 \\
\hline $\mathrm{B}$ & 20 \\
\hline$r$ & 5 \\
\hline
\end{tabular}


rigid circular spline with internal teeth, a wave generator and a flexspline with external teeth. The flexspline is key element in a harmonic drive, because of its periodic elastic deformation caused by the wave generator, whose structure is shown in Fig. 4, the parameters of the structure is listed in Table II. The profile curve of the wave generator is expressed in (1)

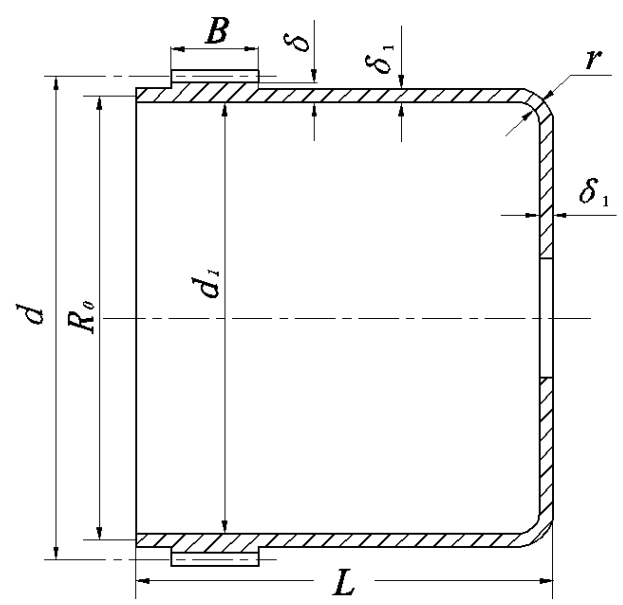

Figure4. Structure of the flexspline

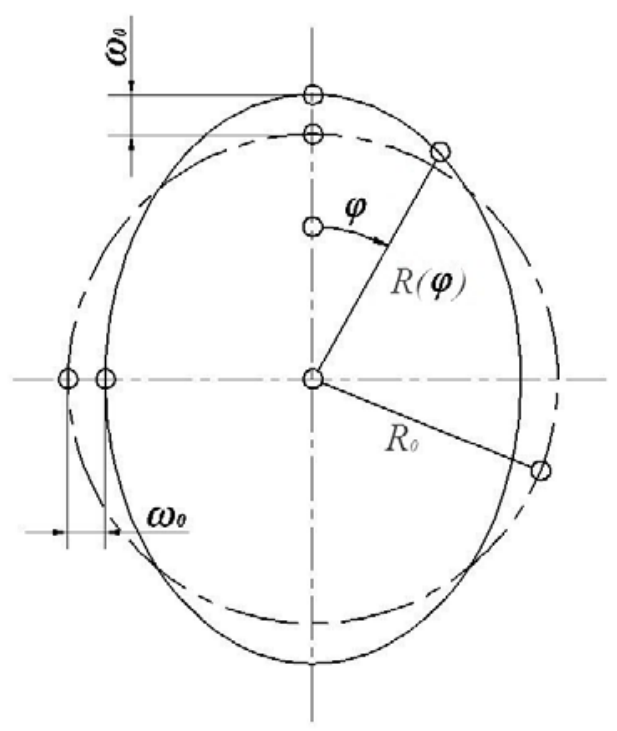

Figure5. The profile of the wave generator

where $R_{0}$ is the radius of flexspline neutral circle; $w_{0}$ is a constant coefficient of the wave generator in Fig. 5; $\varphi$ is the angle measured from the major axis of the wave generator.

In order to mesh the harmonic gear drive components reasonably, the following simplifications are taken on the model:

(1) The connecting flange between the bottom of flexspline cup and output axis is removed. Because it is far from the open end of the cup and gear ring, the deformation of the flexspline is not sensitive to it. The nodes on the ring surface exposed when the connecting flange is removed are coupled to the point on the flexspline axis, which is convenient for defining boundary conditions in ABAQUS.

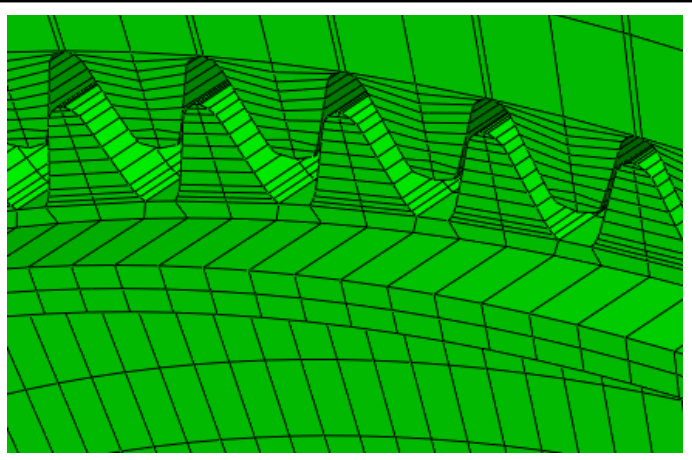

Figure6. The model of harmonic gear drive

(2) The rounded corners between gear ring and cup of flexspline are simplified. However, real tooth profile is adopted for the flexspline tooth to idealize the engagement between the flexspline and circular spline tooth in the process of the dynamic simulation.

(3) In order to install the wave generator into the flexspline conveniently, the wave generator is cut into two equal parts. The outline of wave generator in the axial section is designed to be an arc with a larger radius to simulate the deformation of the outer ring of the flexible bearing.

The simplified model is shown in Fig. 6, the grid is meshed in an intelligent method so that the model can be changed with profiles of the teeth easily.

B. The dynamic simulation method.

To realize the dynamic simulation, the model is discretized, and then the dynamic equation can be used as follows:

$$
\mathbf{M} \ddot{a}(t)+\mathbf{C} \dot{a}(t)+\mathbf{K} a(t)=\mathbf{Q}(t)
$$

where: $\ddot{a}(t)$ and $\dot{a}(t)$ are the acceleration vector and velocity vector of nodes in the system; $\mathbf{M}, \mathbf{C}, \mathbf{K}$ and $\mathbf{Q}(\mathrm{t})$ are the mass matrix, damping matrix, stiffness matrix and joint load vector respectively, which are constituted by unit matrix and vector,

$$
\begin{array}{ll}
\mathbf{M}=\sum_{e} \int_{V_{e}} \rho \mathbf{N}^{T} \mathbf{N} d V & \mathbf{C}=\sum_{e} \int_{V_{e}} \mu \mathbf{N}^{T} \mathbf{N} d V \\
\mathbf{K}=\sum_{e} \int_{V_{e}} \mathbf{B}^{\mathrm{T}} \mathbf{D} \mathbf{B} d V & \mathbf{Q}=\sum_{e}\left(\int_{V_{e}} \mathbf{N}^{\mathrm{T}} \mathbf{f} d V+\int_{S_{\sigma}^{e}} \mathbf{N}^{\mathrm{T}} \mathbf{T} d s\right)
\end{array}
$$

Where $\rho$ is density of material, $\mu$ is damping coefficient, $\mathbf{B}$ is element strain matrix, $\mathbf{D}$ is elastic matrix, $\mathrm{N}$ is unit shape function matrix, $\mathbf{f}$ is unit volume force, $\mathbf{T}$ is forces on borderings.

To solve dynamic differential equation (9), central difference method is adopted to realize numerical integration stepwise. In the central difference method, acceleration and speed can be expressed by displacement,

$$
\ddot{a}_{t}=\frac{1}{\Delta t^{2}}\left(a_{t-\Delta t}-2 a_{t}+a_{t+\Delta t}\right)
$$




$$
\dot{a}_{t}=\frac{1}{2 \Delta t}\left(-a_{t-\Delta t}+a_{t+\Delta t}\right)
$$

Differentiating (11) and (12) to (9) yields the recursive formula

$$
\begin{aligned}
& \left(\frac{1}{\Delta t^{2}} \mathbf{M}+\frac{1}{2 \Delta t} \mathbf{C}\right) a_{t+\Delta t}=\mathbf{Q}_{\mathbf{t}}-\left(\mathbf{K}-\frac{2}{\Delta t^{2}} \mathbf{M}\right) a_{t} \\
& -\left(\frac{1}{\Delta t^{2}} \mathbf{M}-\frac{1}{2 \Delta t} \mathbf{C}\right) a_{t-\Delta t}
\end{aligned}
$$

If $a_{t-\Delta t}$ and $a_{t}$ have been acquired, $a_{t+\Delta t}$ can be calculated by (13), thus (13) is recursive formula which can solve the displacement at each discrete time. When $\mathrm{t}=0, a_{0}$ and $a_{-\Delta t}$ should be determined to calculate $a_{\Delta t}$. Through (11) and (12) we can obtain:

$$
a_{-\Delta t}=a_{0}-\Delta t \dot{a}_{0}+\frac{\Delta t^{2}}{2} \ddot{a}_{0}
$$

After getting the displacement of all points at different time by (13), it is convenient to use geometrical equations and the physical equations to obtain stress and strain at all discrete points.

\section{THE DYNAMIC SIMULATION OF A HARMONIC DRIVE}

Fatigue fracture of the flexspline is the main reason of harmonic gear drives failure, so it is quite important to study the dynamic response of flexspline under alternating loads. In this section, the dynamic simulation of a harmonic drive is conducted, and the stress characteristic and deformation distribution of the flexspline changing with time is extracted. Finally, the reason for the fatigue fracture of the flexspline is analyzes and find out, and the location where the fatigue fracture may happen is predicted.

\section{A. Finite Element Analysis Model.}

C3D8R hexahedral reduction element provided by ABAQUS is choosed to mesh the flexspline, wave generator and rigid spline. Since simplified model has been considered according to the section A, the number of element can be reduced as less as possible to get a better grid quality. The paper obtains the finite element mesh model based on Matlab, which exports input file (*.inp) for ABAQUS calculation. The meshed model is shown in Fig. 7, where is the initial state for solving. The number of elements is 201000 , and number of nodes is 250100 .

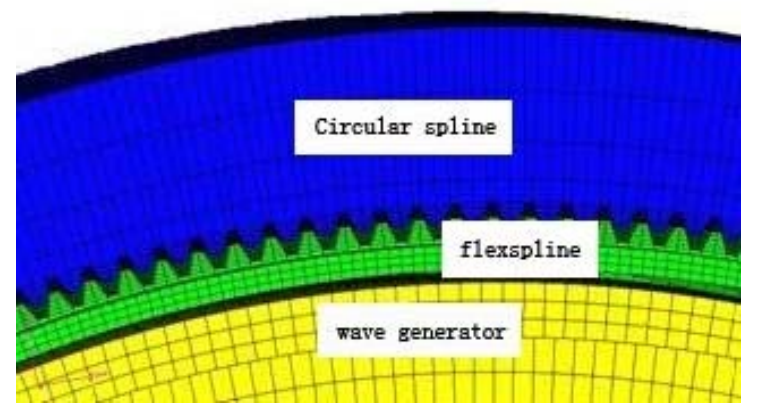

Figure7. Finite element model of harmonic gear
The process of solving the dynamic simulation model is divided into two steps in ABAQUS. The first step is simulating the process that the wave generator be installed into the flexspline. The second step is based on the first step, and add a rated rotating speed $n=3000 \mathrm{rpm}$, and rated load (torque) $\mathrm{T}=300 \mathrm{Nm}$ is applied on the close end of the flexspline cup. Then the contact of wave generator and flexspline and the contact of flexspline tooth and circular spline tooth are defined, and the harmonic gear drive in practice operating is simulated. To ensure the stability of central difference method, set the iteration time $\Delta t \leq L_{\mathrm{e}} / C_{\mathrm{e}}$, where $L_{\mathrm{e}}$ is the smallest length in the minimum element, $C_{e}=(E / \rho)^{1 / 2}$ is the velocity of sound in the medium, and total simulation time is $22 \mathrm{~ms}$ (about the time for the wave generator to turn one circle), to prevent the shock of sudden loading, the first $2 \mathrm{~ms}$ of the process is set to load gradually. The calculation of model is so complex that we have to use DELL 8CPU-16G server to solve it.

\section{B. Stress response of the flexspline cup.}

Fig. 9 shows the curves of Von Mises stress of the 3 nodes on the neutral layer of the flexspline cup changing with time, the positions of the three nodes from 1 to 3 successively lay along the axial of the cup from the open end to the close end of the cup as in Fig. 8, in which node 1 and node 5 locate at the open end and close end of the flexspline cup on the neutral layer respectively, the others locate between them. As the deformation of flexspline changes periodically with time, all nodes of each cross-section which vertical to the axis have the same characteristics of stress and strain in a cycle, the characteristic of each point can represent all nodes of the corresponding section.

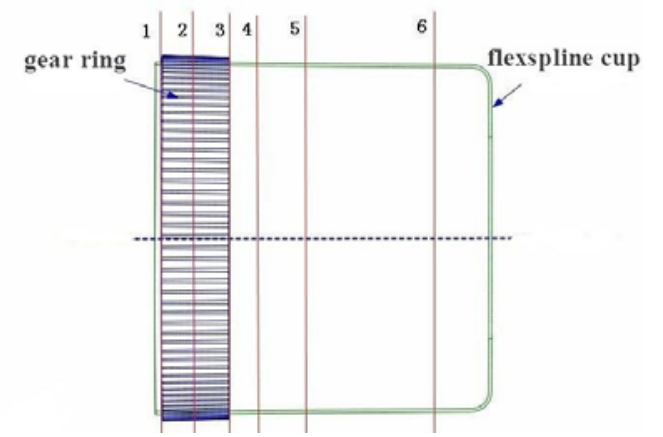

Figure8. The distribution map of analysis section of flexspline cup

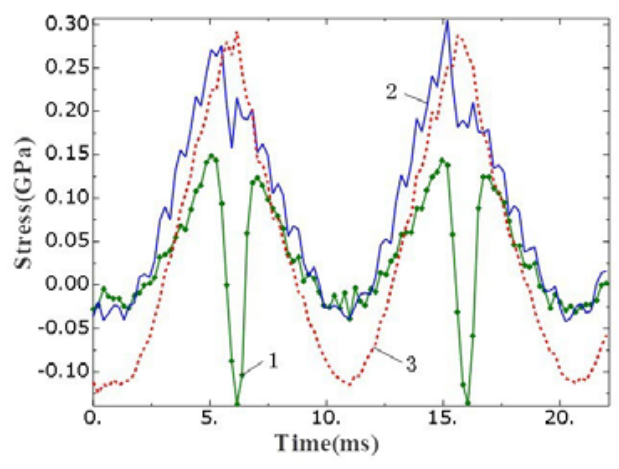

Figure9. The curve of stress-time of flexspline 


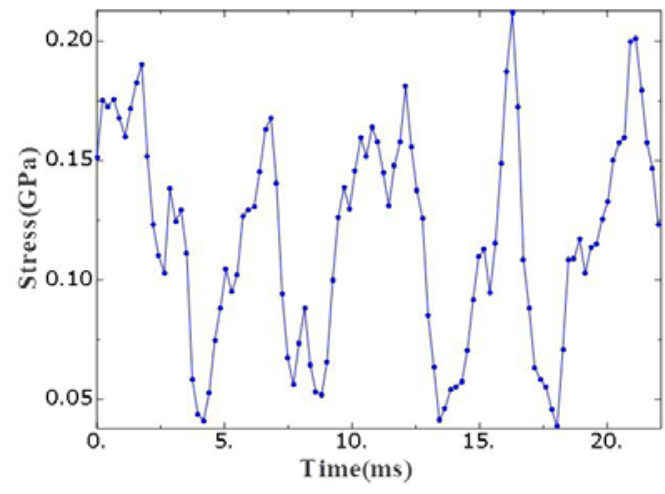

Figure10. The curve of stress-time of Fatigue point

In Fig. 9, the node corresponding to curve 1 locates at the open end of the cup, the strain becomes larger when it is against the minor and the major axis of the wave generator, and there are four peaks in one circle of the wave generator. Towards the close end of the cup, the influence of the minor axis of the wave generator on the flexspline deformation reduces quickly, while the influence of the major axis on that deformation reduces slowly, thus the curve of the flexspline cup stress gradually has two peaks. The nodes corresponding to the thin shell parts of the flexspline are far from the installation position of the wave generator. Hence the stress is small and waves little with time. The maximum stress of node 1 is $223.7 \mathrm{Mpa}$, which is 4.16 times as big as the maximum stress of node 6 , which means fatigue failure is prone to occur in the front part of the flexspline cup.

Curve 1 and curve 3 in Fig. 9 are in the gear ring of the flexspline, the amplitude of alternating stress of its corresponding nodes is $296.1 \mathrm{MPa}$ and $403 \mathrm{MPa}$ respectively. Obviously, the gear ring of flexspline bears huge alternating stress. But curve 1 has four times in alternating in a circle compared with two times in curve 3 , which may lead to fatigue failure. The thickness and depth of gear ring is far bigger than the thickness of thin shell of the flexspline, therefore, the rigidity of the gear ring is great and the stress concentration is prone to occur at the thin shell of the flexspline. The Mises stress of node at the thin shell is extracted, shown in Fig. 10, the alternating amplitude of stress is $230.6 \mathrm{MPa}$, which proves that the transition position of thin shell and the gear ring of the flexspline is the most vulnerable to be fatigue fracture.

\section{B. Distribution of engaging contact force of the flexspline gear ring.}

Due to the different radial deformations of the flexspline along the axial direction, the flexspline tooth becomes skew along the axis direction. Since the spur involut tooth replaced the spatial conjugate tooth form, the conjugate movement of tooth pair is not accurate, and the stress condition of the flexspline becomes quite complicated. The contact forces of Teeth are impossible to be obtained by experiment, the paper obtains the contact force by finite element analysis.

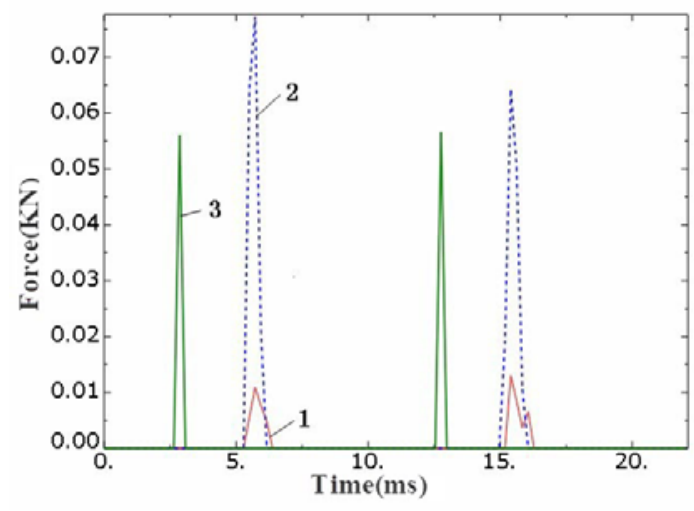

Figure11. The curve of addendum contact force-time of un-optimized tooth profiles with $\left(x_{1}=3.05, x_{2}=2.9\right)$

Distribution characteristics of contact force of the flexspline gear ring. Fig. 11 shows a curve of contact stress on 3 nodes changed with time in one cycle, the 3 nodes are on top of the flexspline tooth in a meshing side of the tooth. They locate along the tooth from node 1 to node 3 , node 1 is close to the front of flexspline gear ring, node 2 is in the middle section, node 3 is in the rear of the flexspline gear ring (Fig. 8). In the initial state the tooth is against the minor axis of the wave generator.

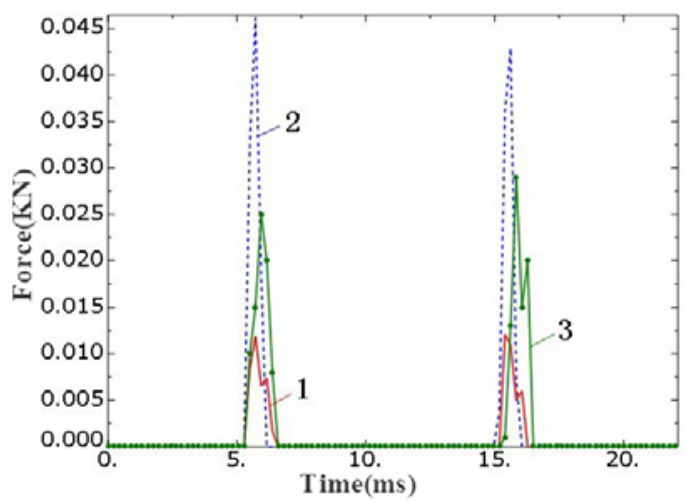

Figure 12. The curve of addendum contact force-time of optimized tooth profiles $\left(x_{1}=3.0494, x_{2}=3.0290\right)$

In the Fig. 11, there are two contact force area in a cycle of the 3 nodes, and contact time is very short, which consists with the characteristics of harmonic gear drive. For the time appear contact force, curve 3 always appears earlier than curve 2 and curve 1 and the amplitude is bigger, because interference at the position of the flexspline tooth begins to engage with the circular spline. Curve 1 and curve 2 show the engagement in the continue meshing area, which means that the main stress locates in the middle part of the profile. The contact forces of the nodes that distribute in the 21 cross-sections in one tooth that in the meshing condition are extracted, the contact forces are shown in Fig. 13, the maximum contact force of the tooth surface $(86.7 \mathrm{~N})$ happens at the middle section, and reduces gradually to the ends. There are some sections near the rear of the tooth that do not engage, this phenomenon consists with that in Fig. 11. 


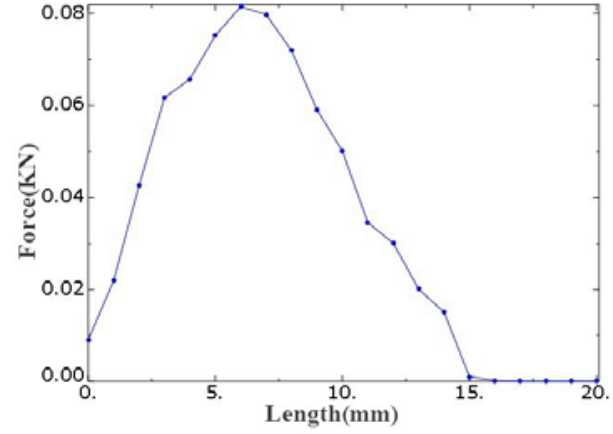

Figure13. The distribution curve of contact force of single un-optimized tooth profile

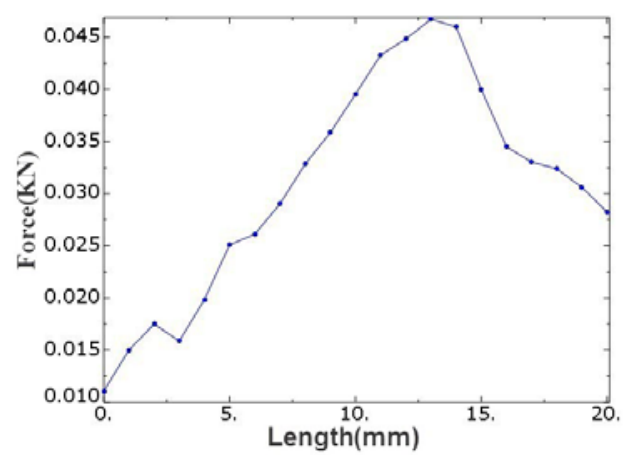

Figure14. The distribution curve of contact force of single optimized tooth profile

Fig. 12 shows a curve of contact stress after optimized on 3 nodes changed with time in one cycle, the three curves all reach peak in the contact force area and the stress is zero at other time, which means the interference phenomenon in Fig. 11 has disappeared. The contact forces of the nodes that distribute in the 21 cross-sections in one tooth after optimized that in the meshing condition are extracted in Fig. 14. Compared with Fig. 13, the contact force area moves to the back-end in general trend, and engagements happen in all the tooth profile. The maximum contact force of the tooth surface reduces $41.9 \%$ compared with un-optimized $(86.7 \mathrm{~N})$.

Distribution characteristics of circumferential load of the flexspline gear ring. Distribution of circumferential load of the flexspline gear ring is the load case of all teeth in the gear ring at a certain time while harmonic gear drive is operating. This can reflect the size and distribution of load on the flexspline at any time.
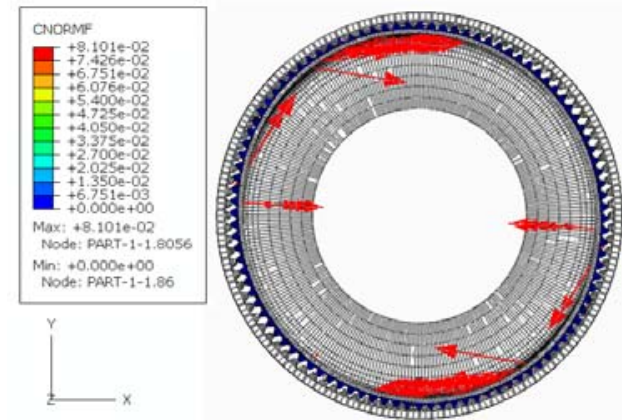

Figure15. The circumferential load distribution of un-optimized flexspline tooth
Fig. 15 shows the distribution of contact forces of all un-optimized flexspline teeth at a certain moment, the length and direction of the red arrows represent the size and the direction of contact force respectively. Fig. 15 tells us the flexspline and circular spline against the long axis of wave generator exist engagement and contact force area. A big contact force exist on each end, this arises from the interference of teeth top of flexspline and circular spline at the engaging moment. The number of tooth pairs participate engagement at the contact force area is 16. After optimized Fig. 16, the number of tooth pairs is 18 , meanwhile, the contact force reduces to $46.99 \mathrm{~N}, 41.9 \%$ less than that before optimization $(81.01 \mathrm{~N})$.
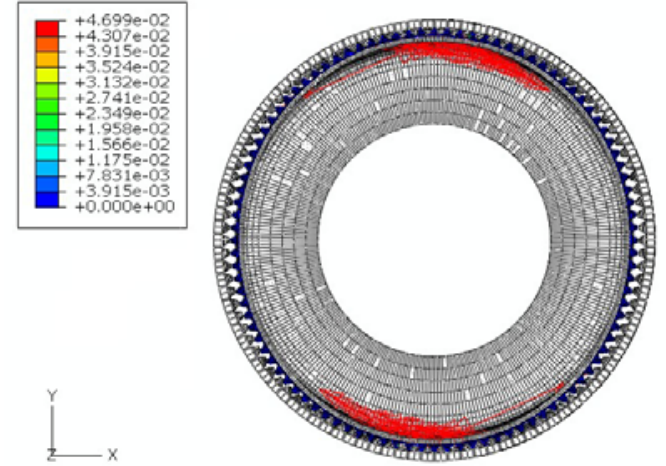

Figure16. The circumferential load distribution of optimized flexspline tooth

As a matter of fact, only $18 \%$ of the total teeth participate in engaging, not reach $40 \% \sim 50 \%$ as $[2,4]$ state so. However, with the increase of the load, the engaged tooth pairs may increase relevantly.

\section{SUMMARY}

(1) The stress on the flexspline cup decreases gradually from the open end to the close end of the cup in the axis direction; Frequency and amplitude of the alternating stress at the open end of the cup are large. Consequently, fatigue failure is prone to occur at the junction of gear ring and thin shell of cup where the stress is concentrated.

(2) In a instant of the operating process of the harmonic drive, the number of teeth which participate engagement is only taking up $18 \%$ of the total teeth number practically, which is much smaller than the results of others [2,4] do not consider dynamic characteristics.

(3) The distribution of contact force on the flexspline ring with optimized tooth profile covers the whole tooth profile along the axial direction, and interference of the tooth pair on the tooth tip at rear of the ring is eliminated; the number of tooth pairs participate engagement at the contact force area increases $4 \%$, at the same time, the contact force reduces $41.9 \%$, meshing characteristics of the tooth pairs are improved greatly.

\section{ACKNOWLEDGMENT}


Authors wish to acknowledge the financial support of the National Natural Science Foundation of P.R. China under Contract No. 50975038.

\section{REFERENCES}

[1] Y. W. Shen and Q. T. Ye, Theory and design of Harmonic Drive Gearing, Beijing, China Machine Press, 1985.

[2] Д.П.Волков, А.Х.Крайнев: Harmonic gear transmission, Electronic industry press, Beijing, 1985.

[3] H., Dong, Study of Kinematics and Meshing Characteristic of Harmonic Gear Drives Based on the deformation Function of the Flexspline. E., Ph.D Thesis, Dalian University of Technology, China, 2008.

[4] Bowen Cui, Y.W.Shen "Study the distribution of contact stress by finite element analysis" [J]. Mechanical transmission, 1997, 21(1): 7-9.

[5] H. M. Dong and X. Q. Zhang, "Experiment based finite element analysis on flexspline of harmonic drive", Journal of Machinery Transmission, Chinese, 100 4- 2539(2001) 02- 0016- 04, 2001.

[6] J., Fu, H., Dong and Y., Shen, Stress Analysis of the Flexspline in Harmonic Gearing by Using FEM. Chinese Mechanical Engineering Society, 18(18):2210-2214, 2007

[7] H. Kazerooni: Dynamics and Control of Instrumented Harmonic Drives. Journal of Dynamic Systems[J], Measurement, and Control, 1995, Vol.117: 15-19.

[8] H., Dong, K. L.,Ting, and D., Wang, 2011, "Kinematic Fundamentals of Planar harmonic drives", ASME J. Mich. Des, 2011.01, pp.0110071-7.

[9] W. Z. Liu, N. R. Zhang, C. L. Zhang, 2006, Finite element analysis of flexspline cup in harmonic drive, Chinese Journal of Mechanical Engineering, 2006, Vol.42: pp.52-55.

[10] K., Oguz, and E., Fehmi, 2007, "Shape optimization of tooth profile of a flexspline for a harmonic drive by finite element modeling," Materials and Design, 28, pp.441-447.

[11] H., Dong, and X., Zhang, 2001, "Experiment based Finite Element Analysis on Flexspline of Harmonic Drive" Chinese J. Mach. Trans., 25(2), pp.16- 19.

[12] C., Musser, 1955, "Strain Wave Gearing," United States Patent Number 2,906,143.

[13] S., Ishikawa, 1967, "The Gear Geometry of Tooth Engagement in Harmonic Drive," Proc. of the JSME Semi-International Symposium, pp.94-104.

[14] K., Kondo, and J.,Takada, 1990, "Study on Tooth Profiles of the Harmonic Drive," Transaction of the ASME, 112 (3), pp.131-137.

[15] Y., Fan, H., Wang, and D., Song, 2002, "Research on Computer Simulation for Conjugate Tooth Profiles of the Harmonic Drive," Chinese J. Nanjing University of Science and Technology, 26(4), pp. 389-392.

[16] H., Dong, D., Wang, and K. L.,Ting, 2011, "Kinematic Effect of the Compliant Cup in Harmonic Drives", ASME J. Mich. Des, 2011.05, Vol. 133 / 051004-1.
Huimin Dong was born in Yuto'an, Hebei, China, 1958-11; Bachelor Degree in 1982, Master Degree in 1985, Ph.D in 2008 at Dalian University and Technology China. The author's major field of study is on the conjugate theory and strength design of mechanical transmission and harmonic drives.

She has been working at School of Mechanical Engineering, Dalian University and Technology China since 1985. In 1997, she was promoted as Associate Professor. Representative publications: Kinematic Fundamentals of Planar harmonic drives, ASME J. Mich. Des, 2011.01, pp.0110071-7 ; Kinematic Effect of the Compliant Cup in Harmonic Drives, ASME J. Mich. Des, 2011.05,Vol. 133 / 051004-1.

Dr. Associate Prof. Huimin Dong is a member of SMEC

Zhengdu Zhu was born in E'zhou, Hubei, China, 1986-09; He is studying at Dalian University and Technology China and will get bachelor degree in 2012 .

Weidong Zhou was born in Hunan, China; Bachelor Degree in 2008 at Dalian University and Technology China. 